\title{
\%
}

\section{EL PROGRAMA DE INCUBADORAS TECNOLÓGICAS DE ISRAEL Y SU PAPEL EN EL DESARROLLO DE LA STARTUP NATION}

El ecosistema empresarial israelí, dinámico e innovador, es estudiado en todo el mundo por su rápido crecimiento en las últimas décadas, así como su éxito en el ámbito internacional. Parte del secreto está en el desarrollo de instrumentos de apoyo a la creación de empresas y para la financiación de la innovación por parte del Gobierno. Este artículo se centra en uno de los programas gubernamentales que más éxito ha tenido, el Programa de Incubadoras Tecnológicas, por tratarse de la principal herramienta en la creación de startups. Así, tras una introducción al sistema empresarial y de innovación israelí, se hace una revisión a fondo de dicho programa, desde sus orígenes hasta su funcionamiento actual y los resultados obtenidos contrastados hasta la fecha.

Palabras clave: innovación, financiación de la innovación, emprendimiento, desarrollo tecnológico, incubación.

Clasificación JEL: O31, O38.

\section{Introducción}

El Estado de Israel recibe desde hace años el sobrenombre de Startup Nation o Silicon Wadi. Esto es así porque en apenas $22.072 \mathrm{~km}^{2}$ de extensión ${ }^{1}$ hay alrededor de 4.770 startups $^{2}$, siendo el país con mayor ratio per cápita de este tipo de empresas. Más aún, Tel Aviv, su

* Representante del Centro para el Desarrollo Tecnológico Industrial (CDTI) en Israel, con base en la Oficina Económica y Comecial de España en Tel Aviv, durante los años 2015 y 2016.

Versión de diciembre de 2016.

1 Esta cifra excluye los territorios palestinos de Cisjordania y la Franja de Gaza.

2 Número de startups cuantificadas por Tel Aviv Global en el año 2015. Recientemente la Autoridad Nacional de Innovación ha establecido una nueva clasificación, por la cual habría 2.000 startups, y 3.000 pequeñas y medianas empresas. A efectos de este artículo se emplean las clasificaciones anteriores. capital financiera, figura en el quinto puesto de los mejores ecosistemas de emprendimiento (Compass, 2015), primera ciudad fuera de Estados Unidos. Y es que Tel Aviv alberga cerca de 1.400 startups, el 30 por 100 del total.

Tal concentración de empresas, por lo general de carácter tecnológico y altamente innovadoras, ha hecho que muchas firmas internacionales tengan puesto el radar en Israel, a la espera de incorporar la tecnología allí desarrollada. En este sentido, algunas de las adquisiciones más conocidas son la de Waze por parte de Google, por valor de 1.000 millones de USD, y la de Trusteer por IBM, por 650 millones de USD, ambas en 2013. No obstante, ya no $\triangleright$ 
son solo las empresas extranjeras las que muestran interés: el año 2015 supuso un punto de inflexión en la historia empresarial israelí, cuando por primera vez empresas israelíes compraron startups locales. A modo de ejemplo, IronSource, líder en la distribución de software libre, ha comprado SuperSonic, empresa especializada en la monitorización de aplicaciones móviles, por 150 millones de USD. Esto es reflejo de que el ecosistema está llegando a un cierto grado de madurez.

Adicionalmente, 2015 fue un muy buen año en cuanto al capital captado por las startups israelíes. Recibieron inversión privada (fondos privados, corporativos, capital riesgo, incubadoras tecnológicas, angels, etcétera) por valor de 4.428 millones de USD en un total de 708 operaciones en 2015 (IVC, 2016).

Ahora bien, ¿qué hay detrás de todo esto? ¿Cómo un país tan pequeño, en extensión y población ${ }^{3}$, ha llegado a convertirse en un referente de la innovación y el emprendimiento? ¿Qué es lo que lleva a los ciudadanos israelíes a emprender? Dar respuesta a estas preguntas no es sencillo, y son muchas las economías que estudian el ecosistema israelí para, en la medida de lo posible, adoptar herramientas similares.

Antes de nada, hay que entender que la economía israelí, desde el comienzo de su historia como Estado hace apenas 68 años, ha sufrido una rápida evolución, pasando de depender de los sectores primario y secundario, a estar basada en el conocimiento y la innovación, impulsada por el sector privado y fuertemente orientada a la exportación (UNESCO, 2016). Dicha evolución ha sido apoyada en gran medida por el Gobierno, siendo un país pionero en la implementación de políticas

\footnotetext{
3 En octubre de 2016 había 8,6 millones de habitantes. Central Bureau of Statistics, www.cbs.gov.il
}

para el fomento de la innovación. Esto le ha situado a la cabeza en las comparativas internacionales en relación al gasto nacional en investigación y desarrollo $(I+D)$, expresado como porcentaje del producto interior bruto $(\mathrm{PIB})^{4}$, hasta el año 2014, en el que la República de Corea desplazó a Israel de su hasta entonces indiscutible primer puesto.

Para llegar a este punto, Israel se centró primeramente en el desarrollo de las universidades y centros nacionales de investigación, hasta colocarse a la cabeza en liderazgo científico. Hecho esto, el Gobierno pasó a crear una industria fuerte e innovadora, para que el conocimiento generado pudiera revertir en beneficio económico, y posicionar al país como líder en innovación y tecnología. Con esta finalidad, en 1969 se estableció, dentro del Ministerio de Industria y Comercio (ahora de Economía, Industria y Competitividad), la Oficina del Jefe Científico (OCS por sus siglas en inglés). La OCS asumió la misión de establecer y gestionar una política transversal de apoyo a la I+D industrial y a la creación de empresas tecnológicas.

Entre los principales logros de la OCS está la aprobación, en 1984, de la Ley de Incentivo a la I+D Industrial, a través de la cual se establecieron una gran variedad de programas de apoyo a la transferencia tecnológica, la I+D y la cooperación. Así, se consolidó como el principal canal de financiación pública para el desarrollo de la alta tecnología, si bien es cierto que su papel principal es el de la definición de la política de $\mathrm{I}+\mathrm{D}^{5}$. La mayor parte del presupuesto es transferido a la industria a través del $\square$

4 Para el año 2015 se estima un gasto nacional en I+D civil de 4,3 por 100 del PIB. El gasto en 2014 fue del 4,1 por 100 del PIB (CBS, 2016).

5 El Gobierno central contribuyó en 2013 a la financiación del 12,5 por 100 de la I+D nacional. El 37,1 por 100 fue financiado por la industria, y casi el 50 por 100 por fondos extranjeros y donaciones. La contribución del Gobierno a la financiación de estas actividades se ha ido reduciendo a lo largo de los años (CBS, 2016). 
Programa Magnet, que fomenta la colaboración entre los sectores industrial y académico, y el Programa de Incubadoras Tecnológicas (en adelante el Programa) (CBS, 2016).

Este último, establecido en 1991, es uno de los que más éxito ha tenido, y el más estudiado por parte de otras economías, ya que se ha erigido como uno de los principales creadores de startups en Israel, dando lugar a cerca de 80 empresas nuevas cada año. Por ello, este documento pretende dar una visión del papel que el Programa ha desempeñado en la creación de la Startup Nation, desde su origen hasta la actualidad.

Para concluir esta introducción, hay que remarcar que, en respuesta a la evolución de la industria israelí, a comienzos del año 2016 se creó la Autoridad Nacional de Innovación (en adelante la Autoridad), que asume la función de la OCS. Como consecuencia, desde 2016 la gestión del Programa y del resto de herramientas gubernamentales de apoyo a la I+D industrial recae sobre la nueva Autoridad.

\section{El modelo israelí de incubación: Programa de Incubadoras Tecnológicas}

\section{1. ¿Qué es una incubadora tecnológica?}

Se entiende como incubadora a una organización que da apoyo a los emprendedores o inventores para que transformen sus ideas en negocios de éxito, poniendo a su disposición una serie de recursos y servicios. En su mayoría son organizaciones con ánimo de lucro, patrocinadas por fondos de capital riesgo, entidades gubernamentales, grandes corporaciones o universidades.

En Israel, el modelo establecido se basa en incubadoras de empresas de base tecnológica, que buscan el desarrollo de ideas innovadoras, disruptivas, y ofrecen servicios tales como financiación, espacio de trabajo, servicios administrativos, asesoramiento tecnológico y de desarrollo de negocio o acceso a una amplia red de contactos, incluyendo potenciales socios e inversores. Allí, estas entidades reciben apoyo gubernamental, a través del Programa, gestionado actualmente por la Autoridad.

Hay que aclarar que existen en el país muchas otras entidades autodenominadas incubadoras. No obstante, a efectos del presente documento, se entiende como incubadoras a aquellas que forman parte del Programa. El resto de entidades de apoyo al emprendimiento en fases tempranas de desarrollo entran en la categoría de aceleradoras, centros de emprendimiento, espacios de co-working, etcétera.

\subsection{Los inicios: creación de una red de incubadoras públicas}

En el año 1991 el Gobierno israelí estableció el Programa de Incubadoras Tecnológicas Públicas (PTIP por sus siglas en inglés), acorde con su estrategia de desarrollar un tejido empresarial amplio e innovador. Su creación responde a la necesidad del momento de integrar en el mercado laboral a cerca de 750.000 inmigrantes de la antigua Unión Soviética, en su mayoría científicos, ingenieros y físicos altamente cualificados. De ahí que en los inicios fuera obligatorio que, para que una incubadora formara parte del PTIP, al menos el 50 por 100 de la plantilla fuera de origen ruso (Frenkel, Shefer y Miller, 2005; Wylie, 2011).

EI PTIP establecía que cada proyecto que entrara en las incubadoras recibiría financiación pública, en forma de préstamo, de hasta el 85 por 100 del presupuesto aprobado. EI $\triangleright$ 
resto del capital debía aportarlo el emprendedor o algún inversor privado, generalmente a cambio de participaciones en la empresa (Frenkel, Shefer y Miller, 2005). El presupuesto gubernamental asignado inicialmente al PTIP era de $2 \mathrm{mi}-$ llones de USD anuales, presupuesto que fue aumentando paulatinamente.

En cuanto a cómo se gestionaba la financiación, el Gobierno daba el préstamo que le correspondía a cada proyecto a la incubadora, quien a su vez lo transfería a los emprendedores. Cuando la empresa finalizaba el periodo de incubación, era la incubadora la encargada de devolver el dinero al Gobierno, dentro de los cuatro años siguientes. Para garantizar el pago, el Gobierno tenía participaciones de cada una de las empresas y, en caso de que la incubadora no devolviera el préstamo, tenía derecho a decidir qué hacer con las acciones (Wylie, 2011). Este sistema de gestión, demasiado complejo, fue modificado posteriormente, como se verá más adelante.

De esta primera versión del Programa resultó la creación de 28 incubadoras tecnológicas en el periodo 1991-1993, repartidas a lo largo del país, orientadas a alimentar el espíritu emprendedor de la población y a fomentar el desarrollo de la alta tecnología. Durante los 10 primeros años (1991-2001), el 86 por 100 de las nuevas startups recibieron apoyo del PTIP, y el 78 por 100 de las mismos consiguieron financiación privada tras la finalización del proceso de incubación (Frenkel, Shefer y Miller, 2005). Estas cifras se consideraron un éxito, y han sido motivo de estudio por parte de muchas otras economías.

Una de las consecuencias más obvias del PTIP fue el desarrollo de sectores de elevado riesgo tecnológico, como el de ciencias de la vida, ya que les dio acceso a capital semilla que de otra forma difícilmente habrían obtenido.
Adicionalmente, el Programa sirvió de herramienta para la promoción de la I+D como estrategia de crecimiento, el desarrollo de las zonas periféricas (Acre, Beersheva, Nazaret...), o la integración parcial de grupos poblacionales minoritarios (árabes, ultraortodoxos, beduinos...).

\subsection{Evolución: proceso de privatización}

El año 2000 supuso un punto de inflexión en el modelo de incubación israelí. La aparición de incubadoras privadas, gestionadas por fondos de capital riesgo y grandes corporaciones, abrió la puerta a nuevas posibilidades para las empresas. Estas incubadoras daban apoyo a proyectos rentables, especialmente en el corto plazo, motivadas por los futuros beneficios, lo que hacía centrarse en sectores concretos.

Ante esta situación, y pese a que el PTIP había dado buenos resultados, el Gobierno vio en el incentivo del beneficio una oportunidad para incrementar la tasa de éxito de las incubadoras del Programa. De esta forma, en el año 2002 inició un proceso de privatización, buscando inversores fuertes que asumieran la propiedad de sus incubadoras, y que fortalecieran las capacidades profesionales y financieras de las mismas. No obstante, para que sectores de mayor riesgo tecnológico y con un retorno más lento no se vieran perjudicados por el nuevo sistema de gestión, el Gobierno decidió seguir dando apoyo financiero. De esta forma, el Programa pasó a ser el Programa de Incubadoras Tecnológicas (TIP por sus siglas en inglés). Desde entonces, el Gobierno aporta el 85 por 100 del presupuesto aprobado para cada iniciativa, y el 15 por 100 restante lo aporta el grupo de gestión o incubadora, a $\triangleright$ 
cambio de participaciones en la empresa. En el año 2002, el presupuesto asignado al Programa era de 32 millones de USD anuales (Frenkel, Shefer y Miller, 2005), y ha ido variando a lo largo de los años en base a la disponibilidad presupuestaria del Gobierno.

Pero, ¿cómo se decidía qué empresas asumieran la propiedad y la gestión de las incubadoras del TIP? El modelo de concesión adoptado entonces consistía en un sistema por franquicias, por el cual un grupo de inversión recibía la licencia para gestionar la incubadora del Programa durante tres años. Pasado ese tiempo, el Gobierno analizaba los resultados y, si la evaluación era positiva, se renovaba la licencia por otros tres años. Sin embargo, este sistema no era óptimo, puesto que en tres años no siempre se recupera la inversión $y$, además, el sistema de renovación de las franquicias no daba pie a la entrada de gestores más competitivos. Por ello, en 2012 se produjeron nuevos cambios, vigentes hasta la fecha.

\subsection{Situación actual del programa}

En la actualidad, las incubadoras que forman parte del Programa son entidades legales independientes, con ánimo de lucro, gestionadas por grupos de inversión privados, pero con apoyo financiero del Gobierno. Desde 2012, su gestión se asigna mediante un sistema de licitaciones, proceso de concurrencia competitiva por el cual nuevos grupos de inversión pueden entrar a formar parte del Programa durante un periodo de ocho años.

Existen un total de 18 incubadoras tecnológicas y 1 biotecnológica dentro del TIP (Tabla 1) a fecha de hoy. Cada una tiene entre 8 y 12 proyectos en incubación, habiendo unos 200 proyectos en marcha en todo momento. En cuanto a los sectores tecnológicos más representados en estas, encontramos que el 36 por 100 son empresas relacionadas con las tecnologías de la información y las comunicaciones (TIC), seguidas por un 35 por 100 de empresas de dispositivos médicos, un 19 por 100 de tecnologías limpias y agrotecnologías, y un 7 por 100 a biotecnología y farmacia (Gráfico 1).

\subsection{1. ¿Cómo es el Programa a día de hoy?}

Para que una empresa entre a formar parte del Programa debe seguir un proceso de evaluación por parte de la incubadora y de la Autoridad, como se especifica en el apartado 2.4.3. Es la incubadora quien elige y gestiona las solicitudes, pero todas las empresas que entran en ella deben ser evaluadas positivamente por la Autoridad. Se espera que una incubadora incorpore al año cuatro nuevas empresas.

El apoyo financiero que recibe cada proyecto oscila entre los 500.000 y los 800.000 USD (Tabla 2), dependiendo del sector tecnológico, a repartir en los dos años que dura el proceso de incubación. Proyectos relativos biotecnológicos, de dispositivos médicos o tecnologías limpias pueden extenderse hasta tres años, aprobándose un presupuesto adicional para este año extra. (Frenkel, Shefer y Miller, 2005; Wylie, 2011).

Del presupuesto aprobado para cada proyecto, el Gobierno proporciona el 85 por 100. A diferencia de en los inicios, la ayuda gubernamental es concedida directamente al empresario, quien devolverá el préstamo, más intereses, en forma de royalties (3-3,5 por 100), solamente en caso de éxito. Los royalties a pagar serán más elevados si los productos derivados de la ayuda gubernamental se producen fuera de Israel. El Gobierno no recibe en ningún caso participaciones de la empresa. (Frenkel, $D$ 
TABLA 1

LISTADO DE INCUBADORAS TECNOLÓGICAS EN ISRAEL

\begin{tabular}{|c|c|c|c|}
\hline Incubadora & Página web & Sectores & Fin franquicia \\
\hline Alon-MedTech Ventures Ltd. & www.alon-medtech.com & Dispositivos médicos, salud & Mayo de 2021 \\
\hline eHelath Ventures & www.eHealthVentures.com & Telemedicina & Marzo de 2024 \\
\hline Galil Ofec Innovation & n.d. & $\begin{array}{l}\text { Dispositivos médicos, TIC, } \\
\text { biotecnología }\end{array}$ & Febrero de 2024 \\
\hline Incentive Incubator Ltd. & www.incentive-il.com & Dispositivos médicos, software & Diciembre de 2020 \\
\hline Incubit Technology Ventures Ltd. & www.incubitventures.co.il & $\begin{array}{l}\text { Dispositivos médicos, TIC, } \\
\text { ciberseguridad, electro-óptica }\end{array}$ & Diciembre de 2020 \\
\hline JVP Cyber Labs & www.jvpvc.com/cyberlabs & Ciberseguridad & Abril de 2021 \\
\hline JVP Media Studio LP & www.jvpvc.com/medialabs & Media, software corporativo & Marzo de 2024 \\
\hline Kinrot Ventures LP & www.hutchisonkinrot.com & Tecnologías limpias & Diciembre de 2021 \\
\hline Medx & www.medxelerator.com & $\begin{array}{l}\text { Dispositivos médicos, } \\
\text { telemedicina }\end{array}$ & Marzo de 2024 \\
\hline MindUp & www.MindUP.co.il & Telemedicina & Febrero de 2024 \\
\hline Nielsen Innovate Fund LP & www.nif.vC & $\begin{array}{l}\text { Internet, comunicaciones, } \\
\text { móvil, media }\end{array}$ & Enero de 2021 \\
\hline NGT-VC 2012 LP & www.ngt3vc.com & Ciencias de la vida & Diciembre de 2020 \\
\hline Sanara Ventures Ltd & www.sanaraventures.com & Dispositivos médicos, salud & Diciembre de 2022 \\
\hline TerraLab Ventures LP & www.terralb.com & $\begin{array}{l}\text { Ciencias de la vida, tecnologías } \\
\text { limpias }\end{array}$ & Diciembre de 2020 \\
\hline The Kitchen & www. TheKitchenHub.com & Industria agroalimentaria & Diciembre de 2022 \\
\hline The Time Innovation Ltd. & www.thetime.co.il & Nuevos medios & Marzo de 2024 \\
\hline Trendlines Medical-Misgav Ltd. & www.trendlines.com/medical/ & $\begin{array}{l}\text { Tecnologías médicas, } \\
\text { agrotecnologías }\end{array}$ & Diciembre de 2023 \\
\hline Van Leer Xenia GP & www.vlx.co.il & Dispositivos médicos, TIC & Marzo de 2021 \\
\hline FuturRx Ltd (incubadora biotecnológica) & www.futurx.co.il & Biotecnología & Diciembre de 2021 \\
\hline
\end{tabular}

\section{GRÁFICO 1}

PESO (\%) DE LOS DISTINTOS SECTORES TECNOLÓGICOS EN LAS INCUBADORAS DEL TIP. AÑO 2015

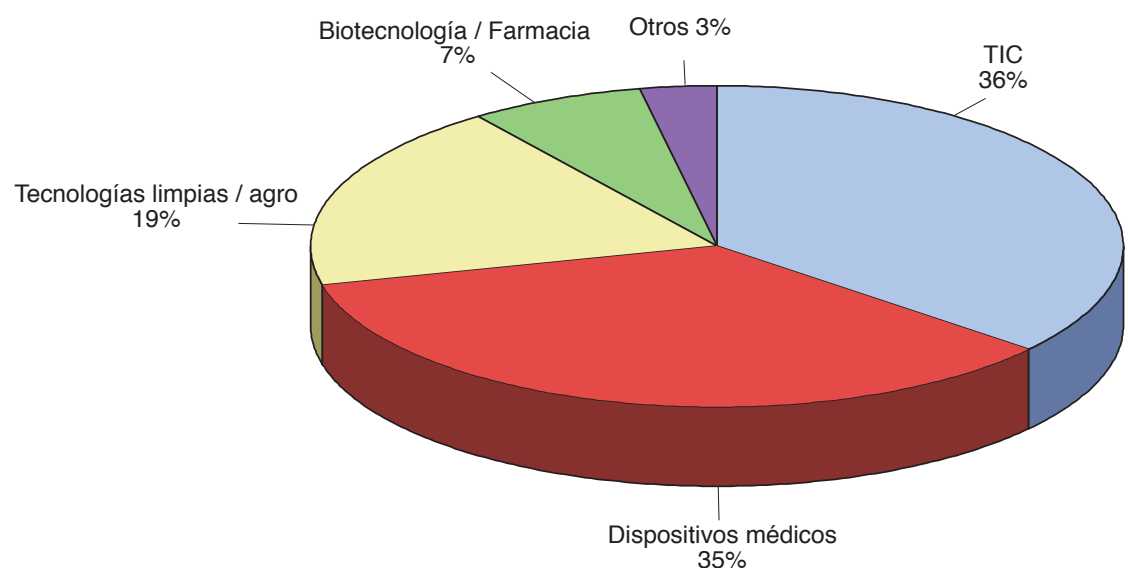

Fuente: elaboración propia a partir de datos de IATI (2015).

Shefer y Miller, 2005; Wylie, 2011). El último presupuesto asignado por parte del Gobierno al Programa del que se tiene constancia fue de 50 millones de USD.
El resto de la financiación, el 15 por 100, corre a cargo de la incubadora a cambio de participaciones en la empresa, de entre el 20 y el 50 por 100 . Además, puede obtener efectivo a $\triangleright$ 
TABLA 2

PRESUPUESTO POR PROYECTO, A REPARTIR EN DOS AÑOS, EN BASE AL SECTOR TECNOLÓGICO, LA LOCALIZACIÓN DE LA INCUBADORA Y EL ORGANISMO FINANCIADOR

(Datos en millones de ILS*)

\begin{tabular}{|c|c|c|c|c|c|c|}
\hline \multirow[t]{2}{*}{ Sector tecnológico } & \multicolumn{2}{|c|}{$\begin{array}{l}\text { Presupuesto total } \\
\text { por proyecto }\end{array}$} & \multicolumn{2}{|c|}{$\begin{array}{l}\text { Financiación gubernamental } \\
\qquad 85 \%\end{array}$} & \multicolumn{2}{|c|}{$\begin{array}{c}\text { Financiación incubadora } \\
15 \%\end{array}$} \\
\hline & Centro & Periferia & Centro & Periferia & Centro & Periferia \\
\hline General & 2,0 & 2,5 & 1,700 & 2,125 & 0,300 & 0,375 \\
\hline Ciberseguridad y tecnologías limpias & 2,2 & 2,7 & 1,870 & 2,295 & 0,330 & 0,405 \\
\hline Dispositivos médicos & 2,5 & 3,0 & 2,125 & 2,550 & 0,375 & 0,450 \\
\hline Biotecnología & 3,0 & 3,5 & 2,550 & 2,975 & 0,450 & 0,525 \\
\hline
\end{tabular}

raíz de fusiones y adquisiciones, salidas a bolsa, etcétera. En caso de que la empresa pueda extender el periodo de incubación a un tercer año, la incubadora deberá hacerse cargo del 15 por 100 del presupuesto correspondiente, mediante fondos propios o de inversores asociados. (Frenkel, Shefer y Miller, 2005; Wylie, 2011).

Pero el apoyo del Gobierno no se queda ahí. A las incubadoras emplazadas en zonas periféricas se les puede llegar a cubrir el 49 por 100 de los costes de operación. Esta concesión tiene forma de préstamo, a devolver cuando la incubadora venda las participaciones de las empresas incubadas. Además, las empresas situadas en dichas incubadoras cuentan con un incentivo extra de 125.000 USD (Frenkel, Shefer y Miller, 2005; Wylie, 2011).

Las incubadoras tecnológicas tienen obligación de operar la incubadora y dar apoyo a sus empresas durante aproximadamente once años, hasta que la última empresa admitida en los ocho años de franquicia finalice el proceso de incubación.

\subsection{2. ¿Cómo se eligen las incubadoras del Programa?}

A la hora de seleccionar a los franquiciados, el Gobierno tiene en cuenta criterios como la experiencia de los accionistas y del equipo directivo; el valor añadido que aportan a las startups; los recursos financieros; el plan de negocio, y los rendimientos anteriores en caso de que hubiera participado previamente en el Programa. En base a la última licitación, los requisitos que deben cumplir los licitantes y sus ofertas son:

- La incubadora debe constituirse como una empresa o sociedad israelí.

- La nacionalidad de los accionistas es indiferente.

-Se da prioridad a las candidaturas de entidades formadas por más de un socio.

-Se ha de presentar un acuerdo de arrendamiento firmado por al menos tres años.

-El espacio arrendado debe tener espacio para alojar a 12 empresas.

- La oferta debe incluir al equipo directivo a tiempo completo: director de la incubadora, de desarrollo de negocio, de tecnología y administrativo.

-Se ha de dar prueba de la disponibilidad de recursos financieros. Esto es así porque la incubadora debe invertir un mínimo de 1,26 millones de ILS ${ }^{6}$ anuales en la gestión. Durante los ocho años de franquicia, la incubadora invertirá 50 millones de ILS o más, tanto en su gestión como en las empresas de su portfolio. $\square$

6 Tipo de cambio a fecha 22/12/2016: 1 ILS $=0,2489$ EUR. Banco Central Europeo. www.ecb.europa.eu 
DIAGRAMA 1

PROCESO DE EVALUACIÓN QUE SIGUE UN PROYECTO DESDE LA ENTRADA EN LA INCUBADORA HASTA SU APROBACIÓN

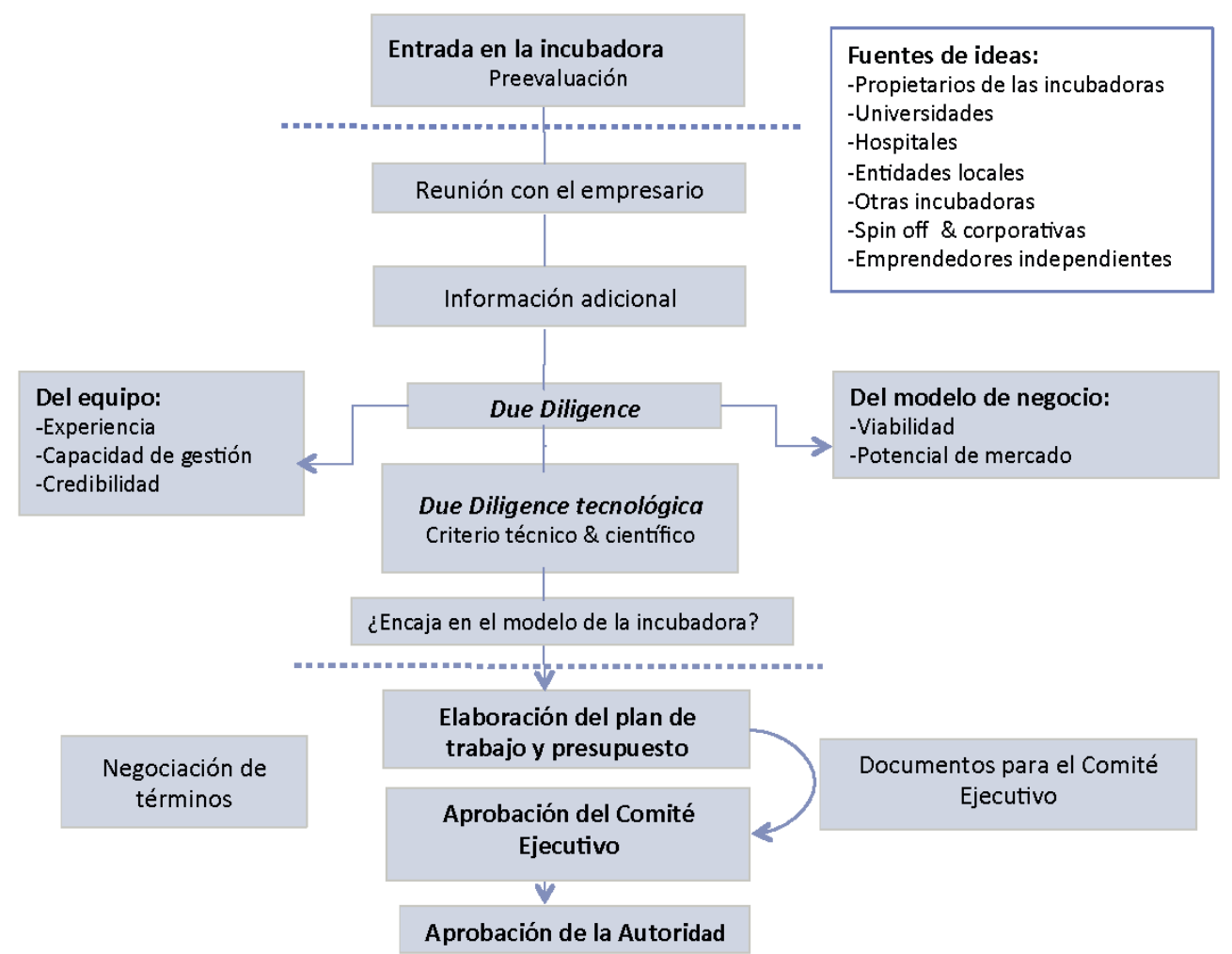

Fuente: adaptado de De Miguel (2012). Informe sobre las incubadoras en Israel 2012. ICEX Estudios e Informes. Disponible en: http://goo.gl/XiXXwg

-Se ha de incluir un plan de negocio detallado: el flujo de inversiones, el comité de inversiones de la incubadora, la estrategia de inversión, proceso de screening y selección, y una política de inversiones complementarias.

-El licitante deberá presentar un aval bancario por valor de 250.000 ILS. Si se gana el concurso, este es sustituido por otro de 1,26 millones de ILS para los ocho años de franquicia. Para incubadoras emplazadas en la periferia el aval es inferior.

\subsection{3. ¿Cuál es proceso que sigue un proyecto hasta entrar en la incubadora?}

Antes de nada, el empresario deberá desarrollar su idea hasta un prototipo del producto o servicio capaz de generar suficiente interés. Para ello, suelen recurrir a familiares y amigos que, a cambio de pequeñas participaciones (5-10 por 100), inyectarán entre 10.000 y 50.000 USD en concepto de capital semilla (seed) (Ramírez, 2013).

Una vez la idea está algo desarrollada, el empresario deberá decidir si acudir a las incubadoras del Programa o hacer uso de otras vías para el desarrollo del proyecto. Si opta por lo primero, tendrá que elegir la incubadora en la que quiere entrar, siendo el criterio más importante a tener en cuenta el equipo de asesoramiento. Hecho esto, presentará su idea a la incubadora, que hará una evaluación preliminar $y$, si pasa este primer corte, la evaluación $\triangleright$ 
de adecuación (Diagrama 1). El proceso de evaluación completo tiene una duración de entre 2 y 3 meses (De Miguel, 2012).

Hay que remarcar que todas las incubadoras cuentan con dos comités formados por profesionales de distintos sectores (ejecutivos, directores de I+D, profesores, jefes de instituciones de I+D, figuras públicas, etcétera), que trabajan aportando sus conocimientos, tiempo y contactos para la evaluación de las propuestas. El primero es el Comité Ejecutivo, que determina la política de funcionamiento de la incubadora; el segundo es el Comité de Inversiones, que evalúa los proyectos candidatos y está formado principalmente por expertos en inversiones early stage (De Miguel, 2012).

$Y$ bien, ¿en qué se fijan los evaluadores cuando entra una idea en la incubadora? En un primer corte, se tienen en cuenta criterios como el grado de innovación tecnológica, la posibilidad de proteger el desarrollo derivado mediante patentes, su potencial en el mercado, la existencia de posibles socios industriales, o la capacidad del equipo directivo de la startup. Si esta evaluación previa, tanto del personal como del negocio, es positiva, el Comité de Inversiones realiza una evaluación más exhaustiva (due diligence o auditoría) antes de que sea revisada por el Comité Ejecutivo de la incubadora (De Miguel, 2012).

Cuando el proyecto recibe luz verde por parte de la incubadora, pasa a ser evaluado por el Comité de Investigación de la Autoridad. Éste evalúa la tecnología presentada, su grado de innovación y el riesgo de la misma, y decide si financiar o no. El resultado de esta evaluación será determinante para que el proyecto sea aceptado en la incubadora (De Miguel, 2012). Si es positivo, la startup podrá iniciar el proyecto.
La incubadora se implica activamente en la gestión de la empresa, introduciendo a uno de sus empleados en la Junta Ejecutiva de la empresa, al menos hasta su graduación. El Gobierno, por su parte, no se involucra en el proyecto.

\subsection{4. ¿Qué hay después?}

Al finalizar el periodo de incubación, la empresa sale al mercado en busca de financiación privada. De ahí que parte de la formación se centre en preparar presentaciones ante inversores, para que estas sean convincentes y atractivas.

Esta segunda fase en la vida de la startup es la que se conoce como early stage, donde necesitan capital suficiente para desarrollar las operaciones de la empresa en el medio y largo plazo. Aquí son los fondos de capital riesgo los principales agentes involucrados. De hecho, el 72 por 100 de la inversión realizada en el año 2015 en startups israelíes la realizaron este tipo de fondos ${ }^{7}$ (IVC, 2016). En función de la suma invertida, se pueden distinguir la serie $A$, con cifras de entre 0,5 y 2 millones de USD, y la serie B, con cifras de hasta 5 millones de USD (Ramírez, 2013).

Una vez la startup tiene un modelo de negocio y un prototipo validado, business angels, fondos de capital riesgo e incluso la banca comercial entran en juego, generalmente hasta que la empresa consiga generar suficiente flujo de caja. Otras opciones, a las que recurren las empresas de nueva creación, son la venta a empresas de mayor envergadura, o la oferta pública inicial (OPI), siendo estas dos alternativas bastante utilizadas por las empresas israelíes.

${ }^{7}$ Los fondos de capital riesgo invirtieron en el año 2015 un total de 3.200 millones de USD, a través de 397 operaciones, en startups israelíes. 
Cabe destacar que el perfil de los inversores en empresas recién salidas de las incubadoras es mayoritariamente internacional. De hecho, el 85 por 100 del capital que reciben la totalidad de las startups israelíes proviene de inversores extranjeros. Esta capacidad de captar fondos extranjeros ha levantado la admiración de muchos países. No obstante, la Autoridad lo ve como una debilidad, puesto que refleja la dependencia del sector tecnológico nacional del exterior, y hace que Israel esté expuesto a los cambios en la economía global y las tendencias del mercado.

\subsection{Impacto en el ecosistema empresarial israelí y retos}

El Programa se ha erigido como uno de los principales fabricadores de startups en Israel, dando lugar a 70-80 empresas nuevas al año. En el periodo 1991-2013, el Gobierno dio apoyo a más de 1.900 empresas, que recibieron financiación pública por valor de 730 millones de USD. De éstas, unas 1.600 finalizaron el proceso de incubación, y el 60 por 100 tuvieron éxito en la captación de financiación privada posterior, aunque solo el 35 por 100 seguían activas a finales de 2013. En ese tiempo, la inversión privada en startups de las incubadoras superó los 4.000 millones de USD (IATI, 2015).

No obstante, pese a la importancia de las startups en el tejido empresarial israelí y su ecosistema de innovación, lo reducido del mercado, la elevada competencia y las dificultades que encuentran a la hora de comercializar sus productos, hacen que solo unas pocas crezcan y alcancen fases avanzadas de desarrollo. A eso ayuda el carácter de los israelíes, altamente innovadores y ambiciosas a la hora de enfrentar retos tecnológicos, pero impacientes en lo relativo a la gestión de sus empresas. A día de hoy, la tasa de supervivencia es de 1 cada 10 startups, pero la tasa de éxito real desciende a 4 de cada 100. De ahí que muchas de ellas nazcan directamente con el objetivo de vender la tecnología desarrollada, para poder iniciar un nuevo ciclo de creación. Sin embargo, en los últimos años, se ha observado un cambio a consecuencia de la experiencia acumulada de empresarios que, tras la creación de dos o más startups, han desarrollado aptitudes para una gestión más duradera de sus empresas.

\section{Las aceleradoras: otras herramientas de apoyo al emprendimiento}

Además de las incubadoras tecnológicas, que cuentan con financiación y soporte público, existen otros agentes que contribuyen a la creación y mantenimiento de la denominada Startup Nation y que no dejan de ser importantes. Entre ellos, destacan las aceleradoras, cuya financiación suele proceder de fondos privados, siendo las más destacadas las aceleradoras corporativas, asociadas a grandes empresas internacionales, y las respaldadas por fondos de capital riesgo. Existen también aceleradoras dependientes de entidades municipales, asociadas a la academia o a organizaciones no gubernamentales. En los últimos años se ha observado un crecimiento en el número de aceleradoras corporativas: Sigma, Barclays, Microsoft, Deutsche Telecom, etcétera.

Desde el punto de vista de los servicios que ofrecen al empresario, hay quien las considera una variante moderna de las incubadoras, aunque más centradas en los sectores de $D$ 
Internet y móvil (Ramírez, 2013). Como las incubadoras, apoyan a los emprendedores con asesoramiento, formación, contactos y, en ocasiones, con una pequeña ayuda financiera. Las principales características diferenciadoras de los programas de aceleración son su duración (máximo seis meses), y el capital que se invierte en las startups (de entre 10.000 y 50.000 USD, a veces a cambio de participaciones).

\section{Conclusiones}

En Israel, a diferencia de otros países, las incubadoras tecnológicas apoyan económicamente cada uno de los proyectos, con sumas relativamente elevadas. El hecho de que formen parte del Programa de Incubadoras Tecnológicas, subvencionado por el Gobierno y gestionado hoy día por la Autoridad Nacional de Innovación, ha sido uno de los puntos clave para llegar a esta posición, y ha tenido fuertes consecuencias.

Por un lado, al asumir el Gobierno gran parte del riesgo que implica invertir en una empresa de base tecnológica de reciente creación, muchos inversores se han atrevido a financiar proyectos de mayor riesgo tecnológico o con un retorno más lento. Como consecuencia, tanto los empresarios como los grupos de inversión gestores de la incubadora, se han visto beneficiados. Adicionalmente, el florecimiento de sectores como el de ciencias de la vida o las tecnologías limpias, y la aparición de empresas biotecnológicas, entre otras, se ha visto altamente favorecido.

Por otro lado, el hecho de que existan incentivos para aquellas incubadoras situadas en áreas periféricas, así como para las empresas que en ellas se emplacen, ha impulsado el desarrollo de dichas áreas, propiciando que la población joven tenga opciones de empleo más allá de emigrar a las grandes ciudades, como Tel Aviv, Haifa o Jerusalén.

Se concluye que, si bien las incubadoras tecnológicas son solo una de las muchas herramientas de las que disponen los empresarios israelíes a la hora de lanzar sus negocios, se pueden considerar una de las que más peso ha tenido en el establecimiento del ecosistema de emprendimiento e innovación israelí.

\section{Bibliografía}

[1] CENTRAL BUREAU OF STATISTICS (2016, febrero). National Expenditure on Civilian Research and Development 1989-2014, [en línea]. Jerusalén: CBS. Disponible en:

https://goo.gl/o1fe/G [Recuperado el 10/11/ 2016].

[2] COMPASS (2015). The Global Startup Ecosystem Ranking 2015, [en línea]. Disponible en:

https://goo.gl/HcGYxb [Recuperado el 15/12/ 2016].

[3] DE MIGUEL, G. (2012). Informe sobre las incubadoras en Israel 2012, [en línea]. Madrid: ICEX Estudios e Informes. Disponible en: http://goo.gl/XiXXwg [Recuperado el 28/08/ 2016].

[4] FRENKEL, A.; SHEFER, D. y MILLER, M. (2005). Public vs. Private Technological Incubator Programs: privatizing the technological incubators in Israel, [en línea]. Haifa: The Samuel Neaman Institute. Disponible en: https://goo.gl/6aB16K [Recuperado el 19/08/2016].

[5] ISRAEL ADVANCE TECHNOLOGY INDUSTRY, IATI (2015). Israels' Life Sciences Industry [en línea]. Disponible en:

https://goo.gl/NprRXX [Recuperado el 22/11/ 2016].

[6] IVC RESEARCH CENTER, IVC (2016). IVC High-Tech Yearbook 2016. Tel Aviv: IVC Research Center Ltd.

[7] RAMíREZ, I. (2013). Ecosistema de innovación y emprendimiento en Israel 2013, [en línea]. Madrid: ICEX Estudios e Informes. Disponible en:

http://goo.gl/b3mqM1 [Recuperado el 13/09/ 2016].

[8] UNESCO (2016). Mapping Research and Innovation in the State of Israel, [en línea] $\triangleright$ 


\section{Carmen Galindo Rodríguez}

París: United Nations Educational, Scientific and Cultural Organization. Disponible en: https://goo.gl/EQsDGp [Recup. el 19/09/ 2016].
[9] WYLIE, C. (2011). «Vision in venture: Israels high-tech incubator program». Cell Cycle, vol.10, $\mathrm{n}^{\circ} 6$, pp. 855-858. 